\title{
Nursing Informatics
}

National Cancer Institute

\section{Source}

National Cancer Institute. Nursing Informatics. NCI Thesaurus. Code C20662.

The application of informatics methods to manage nursing information and improve healthcare. 